\title{
Synthesis of Nanosphere $\alpha-\mathrm{Fe}_{2} \mathrm{O}_{3} / \mathrm{MWCNT}$ composite as Photo-catalyst for the Degradation of Rhodamine B
}

\author{
Zhen Zhao ${ }^{1}$, Xiaowei Zhou ${ }^{1}$, Zhu Liu ${ }^{*}$ \\ School of Yunnan University, Kunming 650091, China; \\ zhaozhen@foxmail.com \\ Corresponding Author: Zhu Liu
}

Keywords: $\alpha-\mathrm{Fe}_{2} \mathrm{O}_{3} / \mathrm{MWCNT}$, hydrothermal method, photocatalytic degradation.

\begin{abstract}
A novel nanosphere $\alpha-\mathrm{Fe}_{2} \mathrm{O}_{3} / \mathrm{MWCNT}$ composite has been prepared by a simple hydrothermal method. The characterization of morphology and structure of $\alpha-\mathrm{Fe}_{2} \mathrm{O}_{3} / \mathrm{MWCNT}$ composite was carried out by scanning electron microscopy, X-ray diffraction and Raman spectroscopy. It is found that MWCNT was well dispersed in spherical nano- $\mathrm{Fe}_{2} \mathrm{O}_{3}$. Furthermore, there is a strong interaction between $\mathrm{Fe}_{2} \mathrm{O}_{3}$ and MWCNTs. The $\alpha-\mathrm{Fe}_{2} \mathrm{O}_{3} / \mathrm{MWCNT}$ composite with 10 wt $\%$ of MWCNT content exhibits optimal photocatalytic activity. For the degradation tests of Rhodamine $\mathrm{B}$, the degradation performance of $\alpha-\mathrm{Fe}_{2} \mathrm{O}_{3} / 10 \%$ wt MWCNT is 11 times that of pure $\alpha-\mathrm{Fe}_{2} \mathrm{O}_{3}$.
\end{abstract}

\section{Introduction}

Rhodamine B as one of the most common dyes will result in many diseases, such as cancer. Semiconductor-based photocatalytic technology had demonstrated the high degrading efficiency for the control of Rhodamine $\mathrm{B}[1,3]$. In numerous semiconductors, $\mathrm{Fe}_{2} \mathrm{O}_{3}$ (hematite) have shown its prospect for photocatalytic and photoelectrochemical purposes due to its abundance, chemical inertness, environmental friendliness, as well as its superior band gap $(2.2 \mathrm{eV})$ and valence band position [4]. However, $\mathrm{Fe}_{2} \mathrm{O}_{3}$ has two important limitations, i.e., a very short hole diffusion length of 2-4 $\mathrm{nm}$ and lower utilization of photo-generated electrons and holes [5].

To address these issues, many methods has been reported to improve the $\mathrm{Fe}_{2} \mathrm{O}_{3}$ photocatalystic efficiency like: tailoring the hematite structure in nanodimension [6], by using heterojunction [7], doping metallic and nonmetallic dopants [8] and etc. Recently, CNTs (carbon nanotubes) draw much attention because of its excellent stability, unique electronic and structural properties $[9,10]$. These advantages make CNTs a promising catalytic assistant material $[11,12]$. However good combination between $\alpha-\mathrm{Fe}_{2} \mathrm{O}_{3}$ and MWCNT has became the challenge.

In this work, we report a novel composite of $\mathrm{Fe}_{2} \mathrm{O}_{3} / \mathrm{MWCNT}$ by direct growth $\mathrm{Fe}_{2} \mathrm{O}_{3}$ on the MWCNT. We demonstrate that this composite photocatalyst exhibits superior photocatalytic performance for the degradation of $\mathrm{RhB}$ [13].

\section{Experimental}

\subsection{Materials}

All chemicals were of analytical grade and used as received without purification. MWCNTs were supplied by Kunming NaTai Energy Co.,Ltd. $\mathrm{Fe}\left(\mathrm{NO}_{3}\right)_{3}, \mathrm{NaOH}$, and ethyl alcohol et al. were purchased from Tianjin Fengchuan. Nanosphere $\mathrm{Fe}_{2} \mathrm{O}_{3}$ was synthesized by hydrothermal method. The preparation procedure is as follows: The precursor was formed by adding $0.012 \mathrm{M} \mathrm{Fe}\left(\mathrm{NO}_{3}\right)_{3}$ to $0.1 \mathrm{M} \mathrm{NaOH}$ aqueous solution dropwise, then the mixture was stirring for another $30 \mathrm{~min}$ at room temperature. The resulting precursor was transferred to a $50 \mathrm{ml}$ Teflon-lined stainless steel autoclave that was sealed, maintained at $160^{\circ} \mathrm{C}$ for $12 \mathrm{~h}$ and cooled down naturally to room temperature. The finally obtained precipitate is nanosphere $\mathrm{Fe}_{2} \mathrm{O}_{3}$. 


\subsection{Characterizations}

The structural characterization of crystalline $\mathrm{Fe}_{2} \mathrm{O}_{3}$ was performed by scanning electron microscopy (FEI Quanta200), X-ray diffraction (TTRIII), transmission electron microscopy (JEM-2100) and Laser Raman measurements (Renishaw invia). In order to demonstrate the photocatalytic performances of the synthetic photocatalysts, photodegradation of RhB was carried out at room temperature under spherical xenon lamp. The initial concentration of RhB solution was 5 $\mathrm{mg} / \mathrm{L}$. Due to its strong absorption at $553 \mathrm{~nm}$, the measurement of the absorbance at $553 \mathrm{~nm}$ vs. The concentration of the RhB solution was carried out to evaluate the degradation efficiency of RhB.

\section{Results and discussion}

The morphologies and microstructure of the $\mathrm{Fe}_{2} \mathrm{O}_{3}$ and $\mathrm{Fe}_{2} \mathrm{O}_{3} / \mathrm{MWCNT}$ are shown in Fig.1.
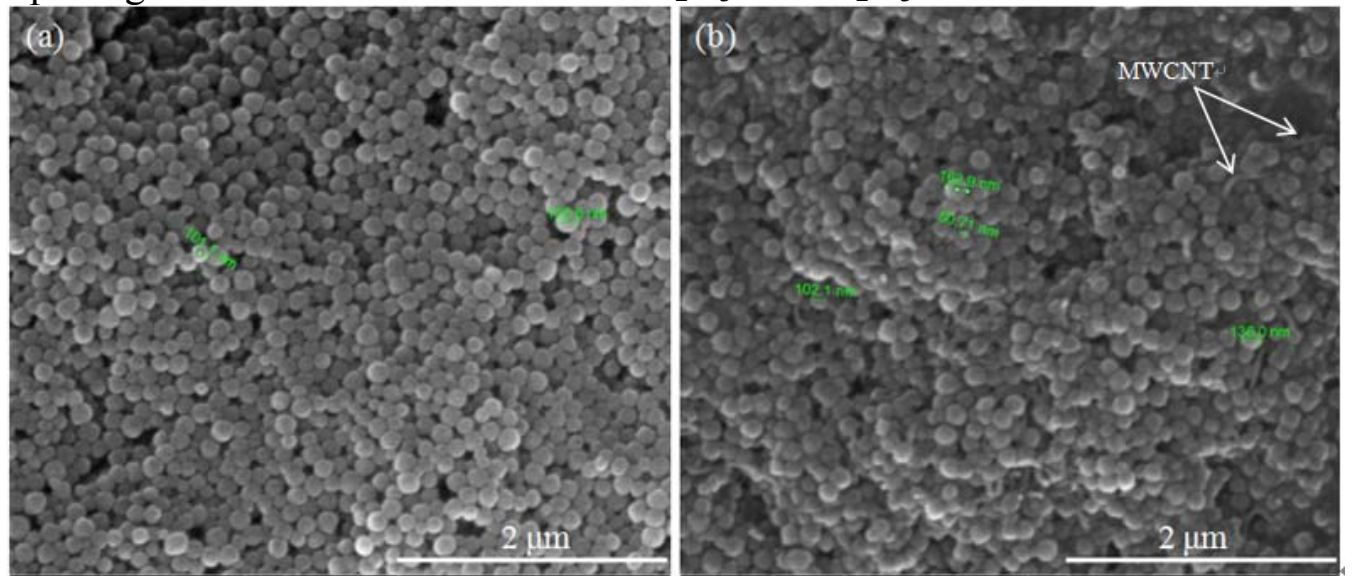

Fig.1 SEM views of (a) $\mathrm{Fe}_{2} \mathrm{O}_{3}$ and (b) $\mathrm{Fe}_{2} \mathrm{O}_{3} / 10 \%$ MWCNT

Fig.1(a) depicts the SEM image of pure $\mathrm{Fe}_{2} \mathrm{O}_{3}$. It can be seen that the diameter of $\mathrm{Fe}_{2} \mathrm{O}_{3}$ particles was about $100 \mathrm{~nm}$. From Fig.1(b), it can be found that MWCNTs was interspersed with $\mathrm{Fe}_{2} \mathrm{O}_{3}$ particles.
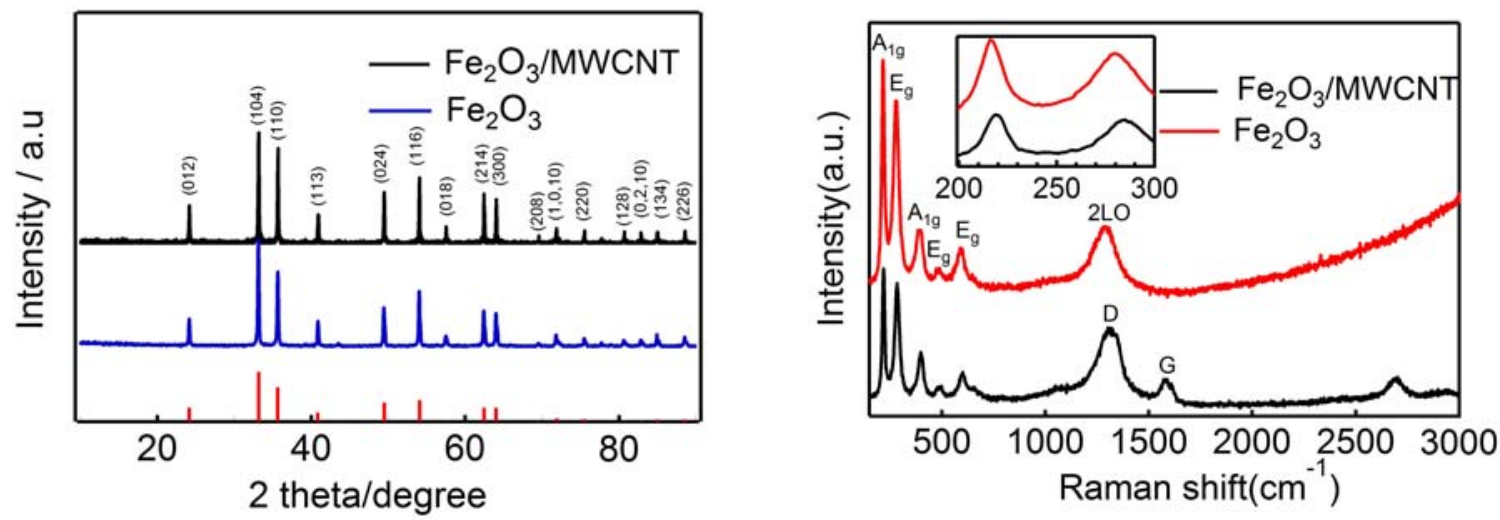

Fig.2 The XRD patterns of $\mathrm{Fe}_{2} \mathrm{O}_{3}$ and $\mathrm{Fe}_{2} \mathrm{O}_{3}$ /MWCNT

Fig.3 The Raman spectra of $\mathrm{Fe}_{2} \mathrm{O}_{3}$ and $\mathrm{Fe}_{2} \mathrm{O}_{3} / \mathrm{MWCNT}$

XRD was used to investigate the phase and crystal structure of the photocatalysts. As shown in Fig.2, the sample diffraction peaks can be well indexed to the alpha phase $\mathrm{Fe}_{2} \mathrm{O}_{3}$. After combing 10 wt $\%$ of MWCNT, no diffraction peaks of MWCNT can be observed in the composite due to the relatively low content of MWCNT[14,16]. There is no change for diffraction peak positions of the $\mathrm{Fe}_{2} \mathrm{O}_{3}$ /MWCNT composite when compared with $\mathrm{Fe}_{2} \mathrm{O}_{3}$, which means that the addition of MWCNTs does not change the crystal structure of $\mathrm{Fe}_{2} \mathrm{O}_{3}$ in the composite. It also suggests that MWCNTs are not incorporated into the lattice of $\mathrm{Fe}_{2} \mathrm{O}_{3}$.

Raman spectroscopy was further carried out to affirm the presence of carbon in $\mathrm{Fe}_{2} \mathrm{O}_{3} / \mathrm{MWCNT}$, as illustrated in Fig.3. MWCNT exhibits D and $\mathrm{G}$ bands at $1339 \mathrm{~cm}^{-1}$ and $1586 \mathrm{~cm}^{-1}$ [17], respectively. For the pure $\mathrm{Fe}_{2} \mathrm{O}_{3}$, six main peaks were detected. $\mathrm{For} \mathrm{Fe}_{2} \mathrm{O}_{3}$, the phonons can be classified as five 
"internal" modes $\left(2 \mathrm{~A}_{1 \mathrm{~g}}+3 \mathrm{E}_{\mathrm{g}}\right)$ [18]. The peak at $1320 \mathrm{~cm}^{-1}$ belongs to two-phonon scattering[19]. After combination with MWCNTs, the $\mathrm{Fe}_{2} \mathrm{O}_{3}$ /MWCNT composite shows a weak Raman shift, which demonstrates the existent direct interaction between MWCNTs and $\mathrm{Fe}_{2} \mathrm{O}_{3}$, indicating the direct contact between $\mathrm{Fe}_{2} \mathrm{O}_{3}$ nanoparticles and MWCNT.

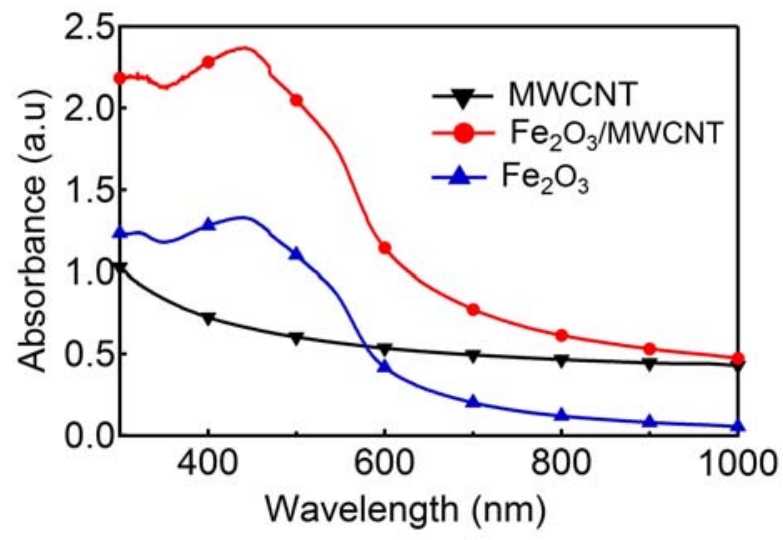

Fig.4 The absorption spectra of $\mathrm{Fe}_{2} \mathrm{O}_{3}$ and $\mathrm{Fe}_{2} \mathrm{O}_{3}$ /MWCNT

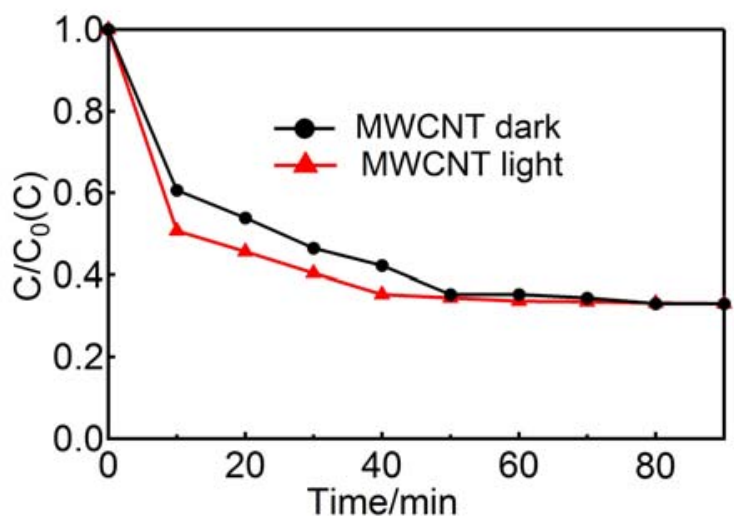

Fig.5 RhB degradation curves (MWCNT)

The $\mathrm{Fe}_{2} \mathrm{O}_{3} / \mathrm{MWCNT}$ will enhance the transportation of charge carriers and widen the absorption spectrum[20]. Fig.4 shows the absorption spectra of $\mathrm{Fe}_{2} \mathrm{O}_{3}$ and $\mathrm{Fe}_{2} \mathrm{O}_{3} / \mathrm{MWCNT}$ composite. It illustrates that the wavelength of the absorption edge for pure $\mathrm{Fe}_{2} \mathrm{O}_{3}$ is determined to be about $586 \mathrm{~nm}$, corresponding to band gap energy $2.2 \mathrm{eV}[21,23]$. The involvement of MWCNT in the composite can strongly enhance the absorbance and widen the strengthen the L-band absorption
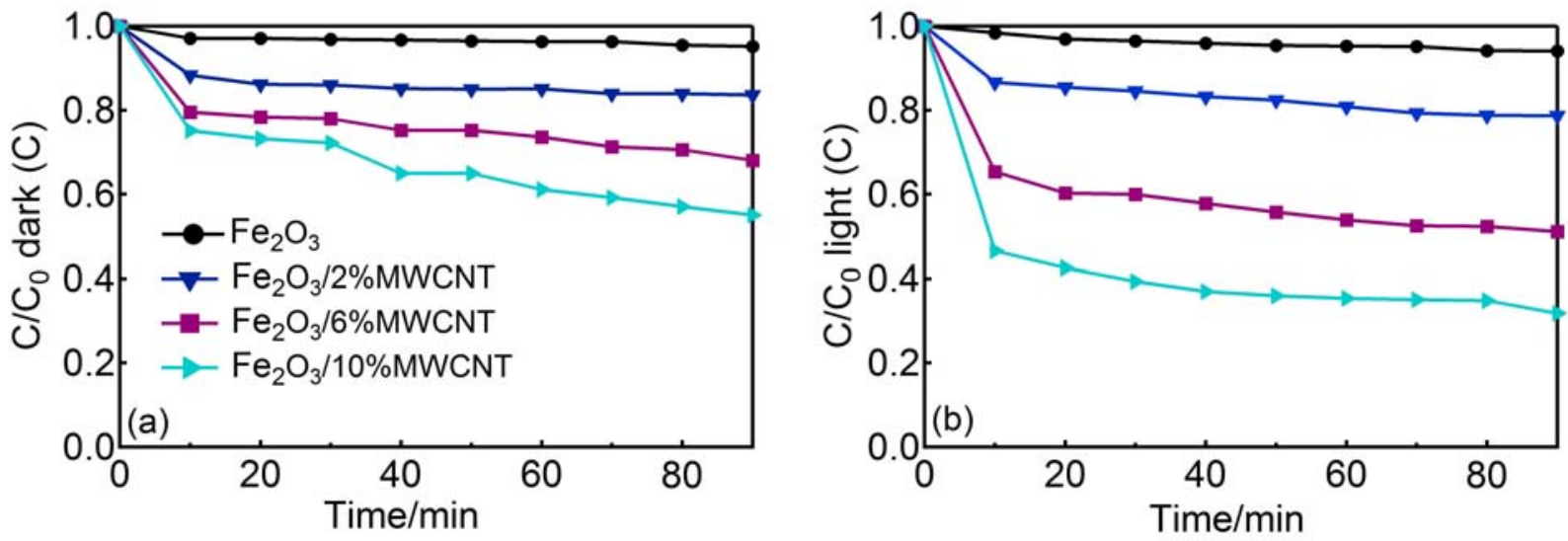

Fig.6 RhB degradation curves without (a) and with (b) irradiation.

The photocatalytic activity of the as-prepared catalysts was evaluated by the degradation of RhB under $500 \mathrm{~W}$ spherical Xenon lamp irradiation. Fig.5 and Fig. 6 presents the photodegradation effects of $\mathrm{RhB}$ with MWCNT, pure $\mathrm{Fe}_{2} \mathrm{O}_{3}$ and $\mathrm{Fe}_{2} \mathrm{O}_{3}$ /MWCMTs. We test the absorbability in darkness as contrast. From Fig.5,we can see that there were not much differences between dark and light conditions, which implied pure MWCNTs has no photocatalystic effect. Fig.6(a) shows the absorbability of $\mathrm{Fe}_{2} \mathrm{O}_{3}$ (dark), $\mathrm{Fe}_{2} \mathrm{O}_{3} / 2 \%$ MWCNT (blue), $\mathrm{Fe}_{2} \mathrm{O}_{3} / 6 \%$ MWCNT (rose red) and $\mathrm{Fe}_{2} \mathrm{O}_{3} / 10 \%$ MWCNT (light green). Fig.6(b) shows the degradation curve. In Fig.6, we can see that pure $\mathrm{Fe}_{2} \mathrm{O}_{3}$ has poor photocataltic activity. After adding MWCNTs, the composites show gradual enhancement of degradation efficiency. With the increasing of MWCNT, composite shows higher degradation efficiency. This is main caused by the lower recombination and absorbability of MWCNTs. $\mathrm{Fe}_{2} \mathrm{O}_{3} / 10 \%$ MWCNT shows $68 \%$ degradation efficiency through $90 \mathrm{~min}$ irradiation and pure $\mathrm{Fe}_{2} \mathrm{O}_{3}$ shows only $6 \%$. 


\section{Summary}

In summary, we have successfully synthesized $100 \mathrm{~nm}$ alpha phase nanosphere $\mathrm{Fe}_{2} \mathrm{O}_{3} / \mathrm{MWCNT}$ composite by a hydrothermal method. The involvement of MWCNT into spherical nano- $\mathrm{Fe}_{2} \mathrm{O}_{3}$ photocatalyst can expand the optical absorption spectrum. For the degradation test of $\mathrm{RhB}$, this $\mathrm{Fe}_{2} \mathrm{O}_{3} / \mathrm{MWCNT}$ composite displays much higher degradation efficiency than pure $\mathrm{Fe}_{2} \mathrm{O}_{3}$. During the following study, we will expand the application of this nanosphere composite into other fields.

\section{References}

[1]. Fujishima A. Electrochemical photolysis of water at a semiconductor electrode[J]. nature, 1972, 238: 37-38.

[2]. Bhunia S K, Jana N R. Reduced Graphene Oxide-Silver Nanoparticle Composite as Visible Light Photocatalyst for Degradation of Colorless Endocrine Disruptors[J]. ACS applied materials \& interfaces, 2014, 6(22): 20085-20092.

[3]. Pelaez M, Nolan N T, Pillai S C, et al. A review on the visible light active titanium dioxide photocatalysts for environmental applications[J]. Applied Catalysis B: Environmental, 2012, 125 : 331-349.Wang G, Ling Y, Wheeler D A, et al. Nano letters, 2011, 11(8): 3503-3509.

[4]. Ling Y, Wang G, Wheeler D A, et al. Sn-doped hematite nanostructures for photoelectrochemical water splitting[J]. Nano letters, 2011, 11(5): 2119-2125.

[5]. Rai S, Ikram A, Sahai S, et al. Morphological, optical and photoelectrochemical properties of Fe 2 O 3-GNP composite thin films[J]. RSC Advances, 2014, 4(34): 17671-17679.

[6]. Hou Y, Zuo F, Dagg A, et al. Visible Light-Driven $\alpha$-Fe2O3 Nanorod/Graphene/BiV1-x Mo x O4 Core/Shell Heterojunction Array for Efficient Photoelectrochemical Water Splitting[J]. Nano letters, 2012, 12(12): 6464-6473.

[7]. M. J. Katz, S. C. Riha, N. C. Jeong, A. B. F. Martinson and J.T. Hupp, Coord. Chem. Rev., 2012,256,2521-29.

[8]. Su D S, Perathoner S, Centi G. Nanocarbons for the development of advanced catalysts[J]. Chemical reviews, 2013, 113(8): 5782-5816.

[9]. Qu Z, Miao L, Wang H, et al. Highly dispersed Fe 2 O 3 on carbon nanotubes for low-temperature selective catalytic reduction of NO with $\mathrm{NH} 3[\mathrm{~J}]$. Chemical Communications, 2015, 51(5): 956-958.

[10]. Zhu T, Wu H B, Wang Y, et al. Formation of 1D hierarchical structures composed of Ni3S2 nanosheets on CNTs backbone for supercapacitors and photocatalytic H2 production[J]. Advanced Energy Materials, 2012, 2(12): 1497-1502.

[11]. Liu Z, Han B. Synthesis of Carbon - Nanotube Composites Using Supercritical Fluids and Their Potential Applications[J]. Advanced Materials, 2009, 21(7): 825-829.

[12]. Ashkarran A A, Fakhari M, Mahmoudi M. Synthesis of a solar photo and bioactive CNT-TiO 2 nanocatalyst[J]. RSC Advances, 2013, 3(40): 18529-18536.

[13]. Sun Z, Yuan H, Liu Z, et al. A Highly Efficient Chemical Sensor Material for H 2S: alphaFe2O3 Nanotubes Fabricated Using Carbon Nanotube Templates[J]. Advanced Materials Deerfield beach then weinheim, 2005, 17(24): 2993.

[14]. Dresselhaus M S, Jorio A, Hofmann M, et al. Perspectives on carbon nanotubes and graphene Raman spectroscopy[J]. Nano letters, 2010, 10(3): 751-758.

[15]. Zhang H B, Lin G D, Zhou Z H, et al. Raman spectra of MWCNTs and MWCNT-based H 2-adsorbing system[J]. Carbon, 2002, 40(13): 2429-2436.

[16]. Shim S H, Duffy T S. Raman spectroscopy of Fe2O3 to $62 \mathrm{GPa}[\mathrm{J}]$. American Mineralogist, 2002, 87(2-3): 318-326.

[17]. Hayashi S, Kanamori H. Infrared study of surface phonon modes in $\alpha-\mathrm{Fe} 2 \mathrm{O} 3$ microcrystals[J]. Journal of Physics C: Solid State Physics, 1980, 13(8): 1529.

[18]. Baratto C, Lottici P P, Bersani D, et al. Sol-gel preparation of $\alpha-F e 2 O 3$ thin films: structural characterization by XAFS and Raman[J]. Journal of sol-gel science and technology, 1998, 
13(1-3): 667-671.

[19]. Massey M J, Baier U, Merlin R, et al. Effects of pressure and isotopic substitution on the Raman spectrum of $\alpha$-Fe 2 O 3: Identification of two-magnon scattering[J]. Physical Review B, 1990, 41(11): 7822.Pradhan G K, Padhi D K, Parida K M. ACS applied materials \& interfaces, 2013, 5(18): 9101-9110.

[20]. Castrucci P, Scilletta C, Del Gobbo S, et al. Light harvesting with multiwall carbon nanotube/silicon heterojunctions[J]. Nanotechnology, 2011, 22(11): 115701.

[21]. Ni C, Bandaru P R. Enhanced optical absorption cross-section characteristics of multi-wall carbon nanotubes[J]. Carbon, 2009, 47(12): 2898-2903.

[22]. Camilli L, Scarselli M, Del Gobbo S, et al. Structural, electronic and photovoltaic characterization of multiwalled carbon nanotubes grown directly on stainless steel[J]. Beilstein journal of nanotechnology, 2012, 3(1): 360-367.

[23]. Shi Y, Li H, Wang L, et al. Novel $\alpha$-Fe2O3/CdS cornlike nanorods with enhanced photocatalytic performance[J]. ACS applied materials \& interfaces, 2012, 4(9): 4800-4806. 